\title{
PRESENTACIÓN DE LA EDICIÓN
}

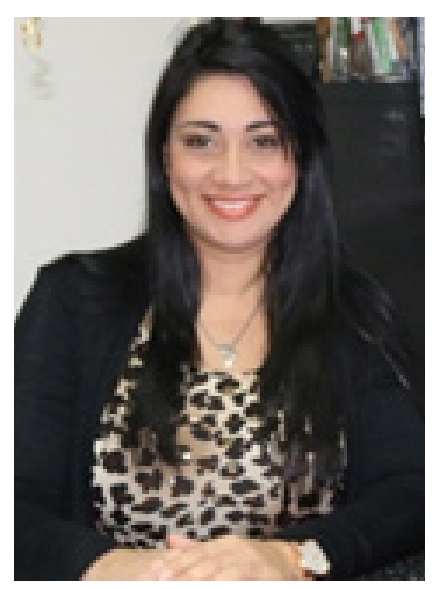

\section{Magdy De las Salas Barroso \\ Editora de la Revista ORATORES \\ oratores@umecit.edu.pa}

La Universidad Metropolitana de Educación, Ciencia y Tecnología (UMECIT), se complace en presentarles nuestra edición número 8 de la Revista ORATORES, correspondiente a Junio 2018 - Noviembre 2018.

La labor del investigador sin duda alguna llega a su punto deseado cuando los resultados de sus esfuerzos investigativos cristalizan en una publicación al servicio de la comunidad científica. Ardua pero gratificante tarea: poder aportar los conocimientos para que puedan servir para solucionar problemas, ampliar teorías, generar nuevas inquietudes de investigación, enriquecer la praxis académica, entre otros logros.

En esta edición un total de seis publicaciones, con autores de diversos continentes inclusive, nos ofrecen sus producciones intelectuales.

Iniciamos con el artículo de investigación presentado por Nerio Ramirez Almarza, de la Universidad Nacional Experimental Rafael María Baralt, Venezuela, ,titulado "TRASCENDENCIA DE LA LÚDICA COMO DIMENSIÓN PSICOESPIRITUAL EN EL PROYECTO DE VIDA DE LOS ACTANTES EDUCATIVOS", concluye en su desarrollo que la lúdica como dimensión psicoespiritual, va a transformar el proceso de enseñanza-aprendizaje, puesto que, son los actantes educativos los protagonistas de dicho proceso; y a su vez como dimensión; ya que encamina al hombre al desarrollo emocional y a los talentos personales, ayudando con ello a alcanzar su felicidad.

Seguidamente tenemos el artículo de Reyes Arturo Valverde, docente de la Universidad Cristiana de Panamá, titulado "RETORNOS ECONÓMICOS REGIONALES Y PROVINCIALES DEL SERVICIO DE INTERNET PARA TODOS”, el cual ofrece datos que permiten analizar cómo en los últimos años Panamá ha crecido económicamente por arriba del 8\%; esto como resultado de perfeccionar su plataforma de servicios ligados al Canal de Panamá. En consecuencia de este alto crecimiento, el país se avoca a reducir la brecha digital que implica 
invertir a nivel nacional y con la firme convicción de que los resultados impulsarán y coadyuvarán a un crecimiento económico.

El ensayo titulado "LAS CONFERENCIAS DOMINICALES EN LA ASOCIACIÓN PARA LA ENSEÑANZA DE LA MUJER: DOS PARADIGMAS HUMANOS" que presenta Juana García Romero, de la Universidad Autónoma de Madrid, España, quien plantea algunos de los pasos fundamentales de la enseñanza de la mujer a partir del decreto de 1868, que permite fundar libremente centros de enseñanza. Hace además referencia a la fundación de la Asociación para la Enseñanza de la Mujer para consolidar el ideal de mujer que propone Fernando de Castro.

“LAS CORRIENTES PEDAGÓGICAS Y LOS DESAFÍOS DE LA EDUCACIÓN" es el ensayo desarrollado por Santos Rengifo, estudiante del Doctorado en Ciencias de la Educación de UMECIT y quien labora en la Institución Educativa Manuel José sierra, Antioquia, Colombia, aborda la educación, en un recorrido que se realiza desde diferentes periodos de la historia de la educación, comenzando desde el siglo de las luces, pasando por la edad de oro, hasta llegar a la educación actual, en esta última se enfatizan diferentes tipos de pedagogías: las emergentes, la de la esperanza y la planetaria, además se realiza un análisis de los filósofos y pedagogos que más se han destacado en cada una de esas épocas

Gino Osellame, docente de la UMECIT y el abogado Jaime Fong Buckridge ofrecen un ensayo titulado "JURIDICIDAD DE LAS ACTUACIONES DE LIQUIDADORES DENTRO DEL RÉGIMEN COOPERATIVO DE PANAMÁ”, en el cual presentan entre sus conclusiones, que el ejercicio de las funciones del liquidador está enmarcadas en instituciones jurídicas definidas como el mandato especial (Derecho Civil) y buenas prácticas de administración general, tal como lo expone de forma prístina el artículo 90 de la Ley 17 de 1 de mayo de 1997, a propósito de la representación legal de la comisión liquidadora, y su relación con la cooperativa.

Finaliza esta edición con Pablo Gómez, docente de la Universidad Nacional Experimental "Rafael María Baralt", Venezuela, quien presenta su ensayo titulado "DECOLONIZACIÓN EDUCATIVA FRENTE AL PENSAMIENTO EUROCÉNTRICO OCCIDENTAL” el cual tuvo entre sus reflexiones algunos elementos para poder entender las posiciones discursivas de estos autores orientados a romper las cadenas mentales que atan a la institución educativa formal a prácticas neocoloniales y proponer un nuevo modelo educativo liberador a partir de la visión emancipadora e historicista circunscrita en una pedagogía crítica de resistencia contra la ideología dominante del sistema opresor.

Amigos lectores, disfruten esta edición de nuestra revista multidisciplinaria ORATORES. 